\title{
Endotoxin Contamination and Reaction Interfering Substances in the Plant Extract Library
}

\author{
Hitomi Kawakami, ${ }^{*, a, b}$ Hiroyuki Fuchino, ${ }^{a, b}$ and Nobuo Kawahara ${ }^{a, b}$ \\ ${ }^{a}$ Tsukuba Division, Research Center for Medicinal Plant Resources, National Institutes of Biomedical Innovation, \\ Health and Nutrition (NIBIOHN); 1-2 Hachimandai, Tsukuba, Ibaraki 305-0843, Japan: and ${ }^{b}$ Graduate School of \\ Pharmaceutical Sciences, Osaka University; 1-6 Yamadaoka, Suita, Osaka 565-0871, Japan. \\ Received June 10, 2020; accepted August 16, 2020
}

Endotoxin is an unintentional contaminant that has numerous activities and can affect various biological experiments using cells. In this study, we measured the endotoxin activity of samples from a plant extract library (PEL) and determined their degrees of contamination. Endotoxin was detected in approx. $48 \%$ $(n=139)$ and approx. $4 \%(n=5)$ of field-collected and crude drug samples, respectively, and in concentrations $>$ 5.0 EU/mL in some samples. The concentrations of endotoxin that affect cells in vitro vary depending on the target cell type. Although the degree of contamination varied in the present study, it was considered to have little effect on the cell experiments. More than 150 PEL samples had problems with reaction courses or recovery rates of Limulus amoebocyte lysate (LAL) tests. In the LAL tests, using three plant extracts [Sanguisorba officinalis L. (Rosaceae), Oenothera biennis L. (Onagraceae), and Lythrum salicaria L. (Lythraceae)], the polyphenolic compounds in the plant extracts affected LAL test and their effects differed depending on the plant species. When the 16 single polyphenol compounds were added to the LAL tests, the compounds with caffeoyl and pyrogallol moieties were found to affect the LAL reaction course and recovery rate. Furthermore, none of the compounds had any effects at concentrations of $1 \mu \mathrm{M}$. Because the plant extracts contained analogs of various polyphenolic compounds, they were presumed to actually act synergistically. Our findings demonstrated that attention must be paid to the recovery rate and reaction process of LAL tests with samples containing polyphenolic compounds.

Key words endotoxin; Limulus amoebocyte lysate (LAL) assay; plant extract library; polyphenol; polyvinylpolypyrrolidone (PVPP)

\section{INTRODUCTION}

The interest in screening using natural products, such as plants and marine products, has increased. Despite the limitations of combinatorial chemistry, the structural diversity of natural products is of great interest. In Japan alone, there are approx. 8800 species of plants, many of which are presently unused species. In 2013, we started constructing a large plant extract library (PEL) and have since prepared over 13000 samples. ${ }^{1)}$ Half of this library consists of Japanese wild plants, followed by cultivated plants, crude drugs, and exotic plants. The PEL is recognized for its great importance due to the potential presence of unknown compounds and different behaviors from single compounds. The PEL has already been used in various screenings, including drug development, food chemistry, and cosmetics development.

Plant extracts are mixtures of components, and endotoxin represents one of the unintended contaminants. Endotoxin is a lipopolysaccharide derived from the surface membrane of Gram-negative bacteria. Endotoxins are known to have cellular-level effects (activation of macrophages, B cells, production of various cytokines, and induction of gene expressions) as well as influence the pyrogenic reaction of the living body. ${ }^{2-4)}$ In recent years, endotoxin contamination in the experimental environment has been reduced by the use of media, reagents, and accessories with low endotoxin levels. Therefore, information regarding the extent of endotoxin contamination in samples is very important for accurate experimental results to be obtained. The presence of endotoxin has been reported in air, soil, and various other environments. ${ }^{5-8)}$ In particular, the underground parts of plants are in contact with the soil, which can lead to contamination by soil microorganisms during the preparation of extracts.

The Limulus amoebocyte lysate (LAL) test is a common method used to measure endotoxin activities because of its high sensitivity, specificity, and wide endotoxin detection range. However, the LAL test utilizes serine protease enzymatic reactions, ${ }^{9,10)}$ and various interfering factors, such as organic solvents, proteases, protease inhibitors, chelators, antibiotics, and metal ions, have been reported. ${ }^{2,3)}$ Polyphenol compounds, which are common plant components, are a group of compounds with varied structures and phenolic hydroxyl groups. Among them, some characteristic polyphenols are known as tannins. Polyphenols and tannins are known to affect enzymatic reactions, ${ }^{11-13)}$ however, no reports have assessed their impacts on the LAL test.

The aim of this study was to determine the extent of endotoxin contamination of the PEL using LAL tests. Additionally, since some extract samples were shown to affect the LAL test, we assessed the effects of polyphenolic compounds on the LAL test and the removal of interfering factors from plant extracts.

\section{MATERIALS AND METHODS}

\section{Materials}

Preparation of PEL and Endotoxin Determination

Chemicals The dimethyl sulfoxide (DMSO) and Limulus 
Color KY Test Wako (endotoxin detection kit) were purchased from FUJIFILM Wako Pure Chemical Corporation (Osaka, Japan). Water for injection (WFI) was purchased from Otsuka Pharmaceutical Co., Ltd. (Tokyo, Japan).

Plant Materials Root samples of Sanguisorba officinalis L. (Rosaceae, Japanese name: Waremoko, MPR-0348) were cultivated in the Tsukuba Division, Research Center for Medicinal Plant Resources (RCMPR), National Institutes of Biomedical Innovation, Health and Nutrition (NIBIOHN) in 2013, and root samples of Oenothera biennis L. (Onagraceae, Japanese name: Mematsuyoigusa, MPR-0366) and Lythrum salicaria L. (Lythraceae, Japanese name: Ezomisohagi, MPR-0363) were collected in Hokkaido in 2013. For the fieldcollected plants, information such as the locations and dates of collection, scientific name, amount of extract, and specimens were recorded and managed by Tsukuba Division, RCMPR, NIBIOHN with unique numbers. The commercial crude drugs were provided by the manufacturers and were deposited at the Tsukuba Division, RCMPR, NIBIOHN. Information regarding the samples was recorded and managed with unique numbers, as with the field-collected plants.

Determination of the Total Phenolic Content FolinCiocalteu reagent and polyvinylpolypyrrolidone (PVPP, Polyclar VT) were purchased form FUJIFILM Wako Pure Chemical Corporation. Milli-Q water was used in the assays (Direct-Q, Merk Millipore, MA, U.S.A.).

Polyphenol Compounds Gallic acid (1), methyl gallate (2), ellagic acid (4), chlorogenic acid (8), rosmarinic acid (9), hesperetin (10) were obtained from FUJIFILM Wako Pure Chemical Corporation. Vanillic acid (3), trans-p-coumaric acid (5), trans-caffeic acid (6), naringenin (11), rutin (13), genistein (14), and puerarin (15) were obtained from Tokyo Chemical Industry Co., Ltd. (Tokyo, Japan). Ferulic acid (7) was obtained from LKT Laboratories (St. Paul, MN, U.S.A.), quercetin (12) was obtained from Cayman Chemical Company (Ann Arbor, MI, U.S.A.), and (+)-catechin hydrate (16) was obtained from Sigma-Aldrich (St. Louis, MO, U.S.A.).

\section{Methods}

Preparation of PEL Samples The plants collected in the field were washed with water, divided into their different parts, dried at $40^{\circ} \mathrm{C}$ for $96 \mathrm{~h}$, and then pulverized. After pulverization, the samples were extracted under reflux with $10 \mathrm{~mL}$ methanol $/ \mathrm{g}$ for $2 \mathrm{~h}$. The extracts were then filtered and concentrated under reduced pressure to produce the residues. The residues were then dissolved in DMSO to a concentration of $40 \mathrm{mg} / \mathrm{mL}$, filtered, and stored in cryotubes at $-20^{\circ} \mathrm{C}$. The crude drug samples were commercial products.

Determination of Endotoxin Activity and Influence on the LAL Test Endotoxins were detected according to the manufacturer's instructions for the reagent. WFI was used to dilute the samples, resulting in the final DMSO concentration in the sample solution being $1 \mathrm{v} / \mathrm{v}(\%)$, and the final plant extract concentrations being $400 \mu \mathrm{g} / \mathrm{mL}$. Samples $(50 \mu \mathrm{L})$ and an equal volume of LAL solution were dispensed into 96well microplates, and incubated at $37^{\circ} \mathrm{C}$. Since plant extracts often contain various interfering factors, recovery tests were performed at the same time. Recovery test samples contained PEL samples, $0.05 \mathrm{EU} / \mathrm{mL}$ CSE (EU: endotoxin unit, CSE: Control Standard Endotoxin). Recovery rate of LAL test was calculated as follows: Recovery rate $(\%)=$ (spiked samplenon-spiked sample) / $0.05(\mathrm{EU} / \mathrm{mL})$. Analyses were conducted

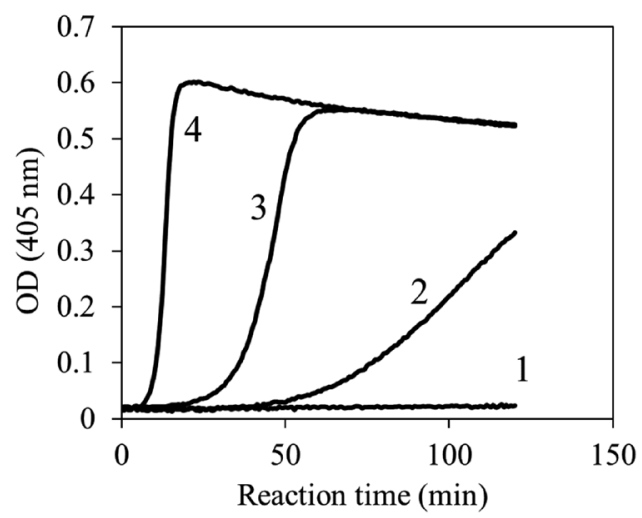

Fig. 1. Reaction Courses of Limulus Amoebocyte Lysate Tests in the Presence of Endotoxin

1, negative control; 2, $0.005 \mathrm{EU} / \mathrm{mL} ; 3,0.05 \mathrm{EU} / \mathrm{mL}$; and 4, $5 \mathrm{EU} / \mathrm{mL}$.

using the Toximaster ${ }^{\circledR}$ QC7 MPR (FUJIFILM Wako Pure Chemical Corporation) software and Sunrise Thermo (Tecan, Mannedorf, Switzerland) microplate reader. The results were converted to the concentration of PEL in the DMSO solution $(E U / m L)$. The results were judged to be appropriate when the recovery rates reached $50-200 \%$ and when the reaction curves showed no deformation (see Fig. 1). Blank samples were prepared using the same protocols described above, without plant samples. The endotoxin concentrations of blank samples were below the detection limit $(<0.0005 \mathrm{EU} / \mathrm{mL})$.

Degradation of Endotoxin in PVPP Endotoxin was decomposed according to Niwa et al. ${ }^{14)}$ with slight modification. Briefly, $40 \mathrm{mg}$ PVPP and $1.5 \mathrm{~mL} 0.1 \mathrm{~N} \mathrm{NaOH}$ $95 \% \mathrm{EtOH}$ were combined and mixed together in $2 \mathrm{~mL}$ plastic tubes, and then stored at $30^{\circ} \mathrm{C}$ (with occasional stirring). After $24 \mathrm{~h}$, the PVPP was washed with WFI after the removal of the $\mathrm{NaOH}$ solution via centrifugation.

Removal of Polyphenols in PEL Samples WFI and PEL samples were added into test tubes with washed PVPP, then stored at $5{ }^{\circ} \mathrm{C}$ for $30 \mathrm{~min}$. The supernatant was used to determine the endotoxin activity, using the protocols described previously.

Determination of the Total Phenolic Content in PEL Samples The total phenolic contents were measured using microplates and the method described by Fujita et al. ${ }^{15)} \mathrm{PEL}$ sample solutions and the 10-fold diluted Folin-Ciocalteu reagent were dispensed into 96-well microplates. After $3 \mathrm{~min}$, $10 \%$ aqueous sodium carbonate solution was added. After standing for $1 \mathrm{~h}$, the absorbance was measured at $700 \mathrm{~nm}$ using a Synergy H1 microplate reader (BioTek Instruments, Inc., VT, U.S.A.). Gallic acid was used as the standard chemical and the results were converted using the concentration of gallic acid in the DMSO solution ( $\mu \mathrm{g}-\mathrm{GA} / \mathrm{mg}$-Ext).

Examination of the Effects of Single Polyphenol Compounds Sixteen polyphenol compounds (see Fig. 2) were added at concentrations of 100,10 , and $1 \mu \mathrm{M}$ and recovery rates were obtained. The recovery rates were calculated in the same formula in the case of PEL samples. To observe the effects of the compounds on the reaction curves, LAL tests with polymyxin B were also performed (final concentration $0.01 \%$ ).

Statistical Analysis Endotoxin measurements of PEL samples were performed in duplicate, and the other 
<smiles>[R]C(=O)c1cc([R1])c(O)c([13CH3])c1</smiles>

$1 \mathrm{R}_{1}=-\mathrm{OH}, \mathrm{R}_{2}=-\mathrm{OH}, \mathrm{R}_{3}=-\mathrm{OH}$

$2 \mathrm{R}_{1}=-\mathrm{OCH}_{3}, \mathrm{R}_{2}=-\mathrm{OH}, \mathrm{R}_{3}=-\mathrm{OH}$

$3 \mathrm{R}_{1}=-\mathrm{OH}, \quad \mathrm{R}_{2}=-\mathrm{OCH}_{3}, \mathrm{R}_{3}=-\mathrm{H}$

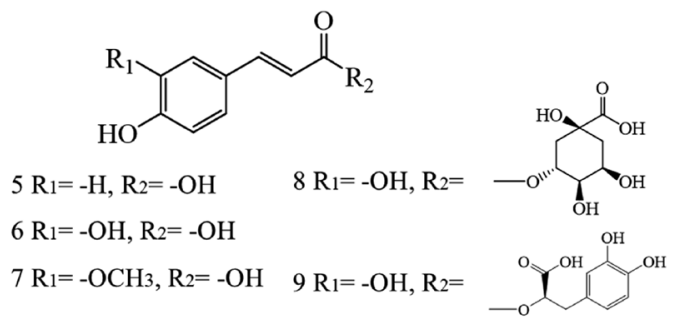<smiles>[R]c1c(-c2ccc(O)c(O)c2)oc2cc(O)cc(O)c2c1=O</smiles>

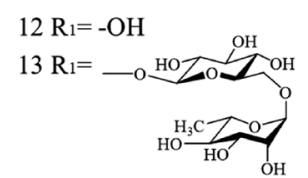<smiles>[R4]c1c(O)cc([R4])c2c(=O)c(-c3ccc(O)cc3)coc12</smiles>

$14 \mathrm{R}_{1}=-\mathrm{OH}, \mathrm{R}_{2}=-\mathrm{H}$<smiles>[R]c1ccc([C@H]2CC(=O)c3c(O)cc(O)cc3O2)cc1[R]</smiles>

$10 \mathrm{R}_{1}=-\mathrm{OH}, \mathrm{R}_{2}=-\mathrm{OCH}_{3}$

$11 \mathrm{R}_{1}=-\mathrm{H}, \mathrm{R}_{2}=-\mathrm{OH}$

Fig. 2. Structural Formulae of Polyphenols

Table 1. Plant Extract Samples Subjected to the Limulus Amoebocyte Lysate (LAL) Test for Endotoxin Detection

\begin{tabular}{|c|c|c|}
\hline \multirow{2}{*}{ Endotoxin activity $(\mathrm{EU} / \mathrm{mL})$} & \multicolumn{2}{|c|}{ Samples } \\
\hline & Field-collected & Crude drugs \\
\hline$<0.05$ & 149 & $121(12)^{a)}$ \\
\hline $0.05-0.25$ & 36 & $3(3)$ \\
\hline $0.25-0.50$ & 16 & 0 \\
\hline $0.50-2.50$ & 42 & $1(1)$ \\
\hline $2.50-5.00$ & 15 & $1(1)$ \\
\hline$>5.00$ & 30 & 0 \\
\hline Total LAL tests that were possible & 288 & $126(12)$ \\
\hline Total samples with endotoxin activity $>0.05 \mathrm{EU} / \mathrm{mL}$ (endotoxin detected) & 139 & 5 \\
\hline Rate of endotoxin detection (\%) & 48.3 & 3.97 \\
\hline Total LAL tests that were not possible & 155 & (24) \\
\hline
\end{tabular}

a) Numbers in parentheses indicate the number of kinds of crude drugs.

measurements were performed in triplicate. Statistical analyses were conducted using Microsoft ${ }^{\circledR}$ Excel $^{\circledR} 2016$ (Microsoft Corp., Redmond, WA, U.S.A.).

\section{RESULTS}

Endotoxin Activity in PEL Samples All measured data are presented in Supplementary Materials. Table 1 shows the number of samples tested using the LAL test. Endotoxin was detected in 139 of the 288 samples collected in the field and in only 5 crude drug samples. The endotoxin activity of samples collected in the field was highly variable, with some exceeding $50 \mathrm{EU} / \mathrm{mL}$. Table 2 shows examples of samples in which endotoxin was detected and Table 3 shows examples of samples for which endotoxin measurement could not be performed. Results that were considered representative from the perspective of sample category (field collected or crude drug), plant species, family name, and endotoxin activity are presented in Tables 2, 3. As shown in Table 2, endotoxin was detected in the plant extracts of various families, and small herbs (e.g. MPR-0269 Chrysosplenium grayanum, MPR-0288 Cymbidium goeringii) and fern plants with complex under- 
Table 2. Examples of Plant Extract Samples for Which the Limulus Amoebocyte Lysate (LAL) Test Was Possible

\begin{tabular}{|c|c|c|c|c|c|}
\hline Sample no. & Scientific name & Family & Plant part ${ }^{a)}$ & Collection site & $\begin{array}{c}\text { Endotoxin } \\
\text { activity } \\
\text { (EU/mL) }\end{array}$ \\
\hline MPR-0022 & Achyranthes bidentata Blume var. fauriei (H. Lév. et Vaniot) & Amaranthaceae & $\mathrm{R}$ & Ibaraki & $<0.05$ \\
\hline MPR-0024 & Cimicifuga simplex (DC.) Wormsk. ex Turcz. & Ranunculaceae & $\mathrm{U}$ & Gunma & $<0.05$ \\
\hline MPR-0033 & Eschscholzia californica Cham. & Papaveraceae & $\mathrm{R}$ & Ibaraki & $<0.05$ \\
\hline MPR-0046 & Mercurialis leiocarpa Siebold et Zucc. & Euphorbiaceae & $\mathrm{W}$ & Ehime & $<0.05$ \\
\hline MPR-0058 & Lysimachia mauritiana Lam. & Primulaceae & $\mathrm{W}$ & Kochi & $<0.05$ \\
\hline MPR-0079 & Justicia procumbens L. var. procumbens & Acanthaceae & $\mathrm{R}$ & Kagoshima & $<0.05$ \\
\hline MPR-0086 & Patrinia scabiosifolia Link & Valerianaceae & $\mathrm{U}$ & Yamanashi & $<0.05$ \\
\hline MPR-0096 & Adenocaulon himalaicum Edgew. & Compositae & $\mathrm{U}$ & Ibaraki & $<0.05$ \\
\hline MPR-0097 & Artemisia japonica Thunb. & Compositae & $\mathrm{U}$ & Hokkaido & $<0.05$ \\
\hline MPR-0119 & Disporum sessile D. Don ex Schult. et Schult.f. var. sessile & Liliaceae & $\mathrm{W}$ & Yamanashi & $<0.05$ \\
\hline MPR-0124 & Maianthemum japonicum (A. Gray) LaFrankie & Liliaceae & $\mathrm{U}$ & Hokkaido & $<0.05$ \\
\hline MPR-0151 & Pteris cretica $\mathrm{L}$. & Pteridaceae & W & Ehime & 0.22 \\
\hline MPR-0155 & Chloranthus serratus (Thunb.) Roem. et Schult. & Chloranthaceae & W & Ehime & 0.12 \\
\hline MPR-0160 & Indigofera trifoliata $\mathrm{L}$. & Leguminosae & $\mathrm{U}$ & Okinawa & 0.13 \\
\hline MPR-0176 & Senecio pseudoarnica Less. & Compositae & $\mathrm{R}$ & Hokkaido & 0.12 \\
\hline MPR-0186 & Nephrolepis cordifolia (L.) C. Presl & Davalliaceae & $\mathrm{W}$ & Kochi & 0.26 \\
\hline MPR-0198 & Plantago asiatica $\mathrm{L}$. & Plantaginaceae & $\mathrm{U}$ & Hokkaido & 0.30 \\
\hline MPR-0204 & Pteris cretica $\mathrm{L}$. & Pteridaceae & $\mathrm{U}$ & Shizuoka & 1.34 \\
\hline MPR-0206 & Leptochilus neopothifolius Nakaike & Polypodiaceae & $\mathrm{U}$ & Kagoshima & 0.72 \\
\hline MPR-0212 & Cimicifuga simplex (DC.) Wormsk. ex Turcz. & Ranunculaceae & $\mathrm{U}$ & Yamanashi & 0.95 \\
\hline MPR-0221 & Papaver dubium $\mathrm{L}$. & Papaveraceae & $\mathrm{R}$ & Ibaraki & 2.17 \\
\hline MPR-0238 & Chrysanthemum pacificum Nakai & Compositae & $\mathrm{U}$ & Shizuoka & 1.07 \\
\hline MPR-0241 & Disporum smilacinum A. Gray & Liliaceae & $\mathrm{W}$ & Nagano & 0.94 \\
\hline MPR-0248 & Cryptotaenia canadensis (L.) DC. ssp. japonica (Hassk.) Hand.-Mazz. & Umbelliferae & $\mathrm{U}$ & Ibaraki & 3.37 \\
\hline MPR-0258 & Cyperus flavidus Retz. & Cyperaceae & $\mathrm{U}$ & Kagoshima & 4.28 \\
\hline MPR-0259 & Hymenophyllum barbatum (Bosch) Baker & Hymenophyllaceae & $\mathrm{W}$ & Ehime & 23.85 \\
\hline MPR-0260 & Lemmaphyllum microphyllum C.Presl & Polypodiaceae & $\mathrm{U}$ & Chiba & 5.96 \\
\hline MPR-0267 & Eschscholzia californica Cham. & Papaveraceae & $\mathrm{R}$ & Ibaraki & 6.21 \\
\hline MPR-0269 & Chrysosplenium grayanum Maxim. & Saxifragaceae & $\mathrm{W}$ & Nagano & 21.50 \\
\hline MPR-0282 & Hemisteptia lyrata (Bunge) Fisch. et C. A. Mey. & Compositae & $\mathrm{R}$ & Ibaraki & 5.96 \\
\hline MPR-0285 & Commelina communis $\mathrm{L}$. & Commelinaceae & $\mathrm{U}$ & Ibaraki & 11.19 \\
\hline MPR-0288 & Cymbidium goeringii (Rchb. f.) Rchb. f. & Orchidaceae & $\mathrm{W}$ & Nagano & 15.74 \\
\hline
\end{tabular}

a) R, root; U, underground part; W, whole plant.

ground structures (e.g. MPR-0259 Hymenophyllum barbatum, MPR-0260 Lemmaphyllum microphyllum) tended to show high activities. However, more than 150 samples (consisting of both field-collected samples and crude drugs) showed poor recovery or non-sigmoidal response curves (see Tables 1, 3). Some plant extracts (e.g. MPR-0022 and 0317 Achyranthes bidentata var. japonica, MPR-0221 and 0327 Papaver dubium) of the same species were measurable, while some were not. It is possible that changes in the components due to differences in the sampling site and sampling time were involved.

Interfering Factors for PEL Samples The samples that could not be measured were classified as follows: (1) samples with large meandering reaction curves, and (2) samples with similar reaction curves to the sigmoidal type with abnormal recovery. We, therefore, selected polyphenol study samples from each group. Sanguisorba officinalis and L. salicaria corresponded to (1), O. biennis corresponded to (2). In addition, $S$. officinalis was selected because strong inhibitory activities were observed in multiple samples, and $O$. biennis and $L$. salicaria were selected because Onagraceae and Lythraceae are considered to contain a large amount of polyphenol compounds. ${ }^{16-19)}$

Figure 3 shows the reaction curves of the LAL test when three PEL plant extracts (root samples of $S$. officinalis L., $O$. biennis L., and L. salicaria L.) were added. The normal kinetics response to endotoxin was depicted in a sigmoid form with lagging (Fig. 1). Sanguisorba officinalis and L. salicaria showed meandering curves (Figs. 3A1, C1). Although the reaction curve of $O$. biennis resembled a sigmoidal form, its recovery was $285 \%$. Dilution of the samples did not remove these interfering reactions. Furthermore, the addition of polymyxin B did not affect the reaction curves (Figs. 3A1, 2, B1, $2, \mathrm{C} 1,2)$. When the extracts treated with PVPP were added, sigmoidal reaction curves were observed (Figs. 3A3, B3, C3). Figure 4 shows the total amount of polyphenols in the three plant extracts. The polyphenol content of the three extracts was reduced by one-tenth after PVPP treatment.

Effects of Polyphenol Components on the LAL Test Table 4 shows the effects of polyphenolic compounds on the LAL test. Because tannin has many structural isomers, 
Table 3. Examples of Plant Extract Samples for Which the Limulus Amoebocyte Lysate (LAL) Test Was Not Possible

\begin{tabular}{|c|c|c|c|c|c|}
\hline Sample no. & English name or scientific name & Family & Plant part ${ }^{a)}$ & Collection site & Category \\
\hline & Rhubarb & Polygonaceae & $\mathrm{Rh}$ & & Crude drug \\
\hline & Coptis Rhizome & Ranunculaceae & $\mathrm{Rh}$ & & \\
\hline & Astragalus Root & Leguminosae & $\mathrm{R}$ & & \\
\hline & Glycyrrhiza & Leguminosae & $\mathrm{R}$ & & \\
\hline & Bupleurum Root & Umbelliferae & $\mathrm{R}$ & & \\
\hline & Japanese Gentian & Gentianaceae & $\mathrm{R}$ & & \\
\hline & Atractylodes Lancea Rhizoma & Compositae & $\mathrm{Rh}$ & & \\
\hline & Ginger & Zingiberaceae & $\mathrm{Rh}$ & & \\
\hline & Processed Ginger & Zingiberaceae & $\mathrm{Rh}$ & & \\
\hline MPR-0290 & Lycopodium clavatum L. var. nipponicum Nakai & Lycopodiaceae & $\mathrm{U}$ & Hokkaido & Field collected \\
\hline MPR-0293 & Asplenium scolopendrium L. ssp. japonicum (Kom.) Rasbach, Reichst. et Viane & Aspleniaceae & $\mathrm{U}$ & Hokkaido & (Ferns) \\
\hline MPR-0294 & Ctenitis subglandulosa (Hance) Ching & Dryopteridaceae & $\mathrm{U}$ & Kagoshima & \\
\hline MPR-0295 & Cyrtomium falcatum (L.f.) C.Presl & Dryopteridaceae & $\mathrm{U}$ & Kagoshima & \\
\hline MPR-0305 & Persicaria debilis (Meisn.) H. Gross ex W. T. Lee & Polygonaceae & $\mathrm{R}$ and $\mathrm{S}$ & Nagano & Field collected \\
\hline MPR-0308 & Rheum rhabarbatum $\mathrm{L}$. & Polygonaceae & $\mathrm{U}$ & Ibaraki & (Angiosperms) \\
\hline MPR-0317 & Achyranthes bidentata Blume var. japonica Miq. & Amaranthaceae & $\mathrm{R}$ & Ibaraki & \\
\hline MPR-0326 & Triadenum japonicum (Blume) Makino & Guttiferae & $\mathrm{U}$ & Hokkaido & \\
\hline MPR-0327 & Papaver dubium $\mathrm{L}$. & Papaveraceae & $\mathrm{R}$ & Ibaraki & \\
\hline MPR-0334 & Sedum sarmentosum Bunge & Crassulaceae & $\mathrm{W}$ & Nagano & \\
\hline MPR-0343 & Agrimonia pilosa Ledeb. var. japonica (Miq.) Nakai & Rosaceae & $\mathrm{U}$ & Ibaraki & \\
\hline MPR-0348 & Sanguisorba officinalis L. & Rosaceae & $\mathrm{U}$ & Ibaraki & \\
\hline MPR-0349 & Sanguisorba officinalis $\mathrm{L}$. & Rosaceae & $\mathrm{U}$ & Ibaraki & \\
\hline MPR-0354 & Lespedeza cuneata (Dum. Cours.) G. Don & Leguminosae & $\mathrm{R}$ & Yamanashi & \\
\hline MPR-0359 & Euphorbia lathyris $\mathrm{L}$. & Euphorbiaceae & $\mathrm{U}$ & Ibaraki & \\
\hline MPR-0363 & Lythrum salicaria $\mathrm{L}$. & Lythraceae & $\mathrm{R}$ & Hokkaido & \\
\hline MPR-0366 & Oenothera biennis L. & Onagraceae & $\mathrm{R}$ & Hokkaido & \\
\hline MPR-0373 & Lysimachia clethroides Duby & Primulaceae & $\mathrm{U}$ & Ibaraki & \\
\hline MPR-0400 & Aster leiophyllus Franch. et Sav. var. leiophyllus & Compositae & $\mathrm{U}$ & Yamanashi & \\
\hline MPR-0422 & Iris ensata Thunb. var. spontanea (Makino) Nakai ex Makino et Nemoto & Iridaceae & $\mathrm{U}$ & Hokkaido & \\
\hline MPR-0423 & Iris pseudacorus L. & Iridaceae & $\mathrm{U}$ & Ibaraki & \\
\hline
\end{tabular}

a) $\mathrm{Rh}$, rhizome; R, root; U, underground part; S, stem; W, whole plant.

we first tested the low molecular weight polyphenolic compounds that contain components of tannins. Several flavonoid glycosides were also included in the test, since the solubility of compounds in water is considered to be an important point when studying the effects of enzymes. Deformation of the reaction curves and recovery rates outside of the acceptable range was observed with the addition of 10 of the 16 compounds. Reduced recovery rates were observed for four phenylpropanoids [trans-caffeic acid (6), ferulic acid (7), chlorogenic acid (8), and rosmarinic acid (9)] at $100 \mu \mathrm{M}$. Chlorogenic acid (8) and rosmarinic acid (9) showed decreases in absorbance at $405 \mathrm{~nm}$ after the addition of LAL, and the reaction solution turned blue. Gallic acid (1), methyl gallate (2), and rutin (13) at $100 \mu \mathrm{M}$ also caused deformation of the reaction curves.

$(+)$-Catechin (16), flavanones [hesperetin (10) and naringenin (11)], vanillic acid (3), trans-p-coumaric acid (5), and puerarin (15) did not affect the recovery rates and the reaction curves at concentrations of $1-100 \mu \mathrm{M}$. None of the compounds had an effect at the $1 \mu \mathrm{M}$ concentration.

\section{DISCUSSION}

In this study, we measured the endotoxin activity in PEL and clarified the degree of contamination. In addition, since the normal measurement could not be performed in more than half of the samples, we examined the influence of polyphenol compounds, which can affect enzyme activity, on the LAL test.

The degree of endotoxin contamination differed between field-collected samples and crude drugs. Although endotoxin was detected in half of the measurable field- collected samples, endotoxin was detected in only five of the crude drugs (Table 1). In the case of the crude drugs, processing, such as peeling and washing, are performed prior to the time of distribution. ${ }^{20)}$ However, because field-collected samples are only washed with water after collection, contamination by endotoxins can occur.

Inagawa et al. ${ }^{21)}$ detected endotoxin in all 62 crude drugs by extraction with hot water, and $\mathrm{Hsu}$ and $\mathrm{Fu}^{22}$ detected endotoxin in approx. $20 \%$ of 35 crude drugs by extraction with cold water. Compared with their results, the PEL samples in the present study showed a lower endotoxin activity. Differences in extraction solvents presumedly account for the differences in the results obtained in the present and previous studies. When $0.5 \mathrm{ng} / \mathrm{mL}$ lipopolysaccharide (LPS) (O55: B55) was suspended in water and methanol and heated for $2 \mathrm{~h}$, LPS was detected in the water, not in the methanol (data not shown). The concentration of endotoxin that affects cells in vitro varies greatly depending on the targeting cell type. 

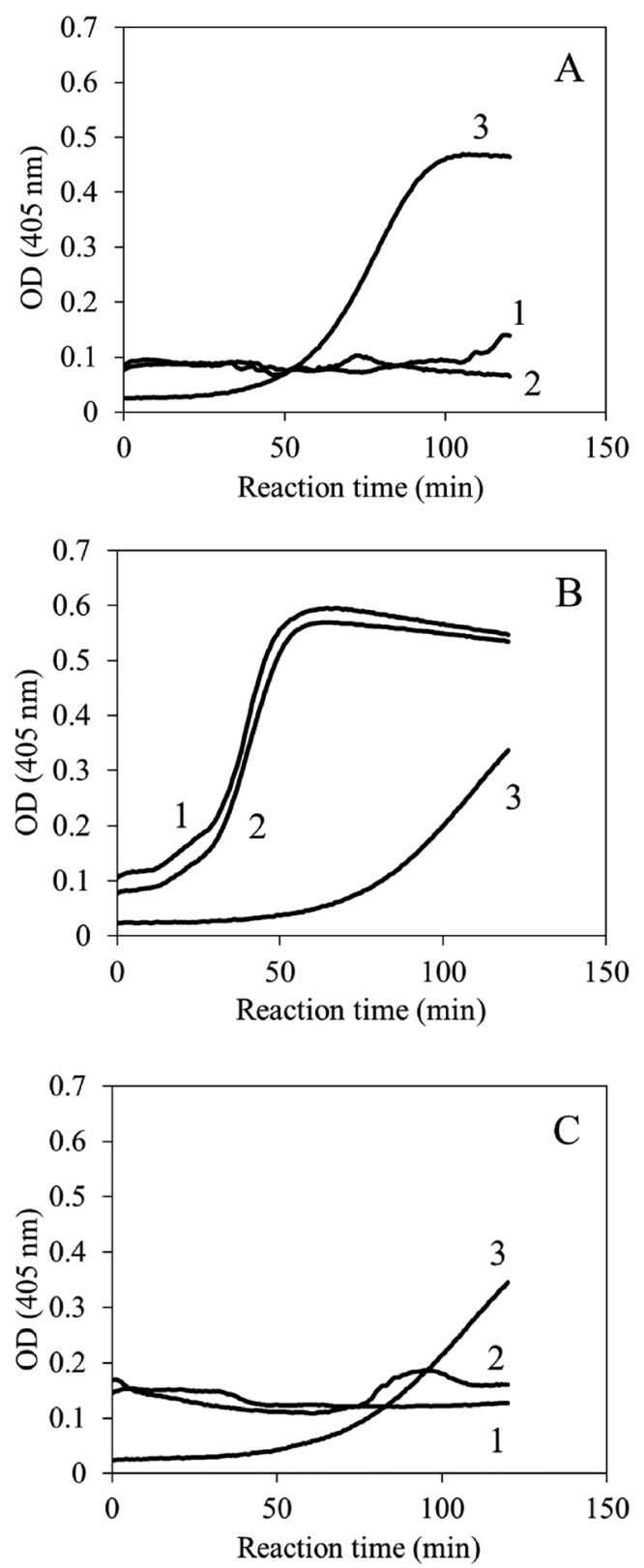

Fig. 3. Reaction Courses of Limulus Amoebocyte Lysate Tests with Plant Extracts

A, $400 \mu \mathrm{g} / \mathrm{mL}$ Sanguisorba officinalis; B, $400 \mu \mathrm{g} / \mathrm{mL}$ Oenothera biennis; and C, $400 \mu \mathrm{g} / \mathrm{mL}$ Lythrum salicaria. Plant extract conditions were as follows: 1, plant extract with no treatment; 2 , plant extract and $0.01 \%$ polymyxin $\mathrm{B}$; and 3 , plant extract treated with PVPP.

Guo et al. $^{23)}$ reported that the viability of MC3T3-EI cells decreased in the presence of endotoxins at concentrations greater than $10 \mathrm{ng} / \mathrm{mL}$. Zhang et al. $^{24)}$ reported that endotoxin, at a concentration of $100000 \mathrm{ng} / \mathrm{mL}$, caused platelet aggregation in the presence of thrombin. Since endotoxins have different activities depending on the type of bacteria, simple comparisons are difficult. When using the conversion $1 \mathrm{ng}=5$ to 10 $\mathrm{EU}^{25)}$ the reported value of Guo et al. ${ }^{23)}$ corresponds to 50 to $100 \mathrm{EU} / \mathrm{mL}$, and that of Zhang et al. ${ }^{24)}$ corresponds to 500000 to $1000000 \mathrm{EU} / \mathrm{mL}$. In addition, the effects of endotoxins on other cells such as NK cells and fibroblasts ${ }^{26-29)}$ have been reported, however, the effects are limited to relatively high doses. These results suggested that most of the PEL samples would not affect experiments with cells. However, some sam-

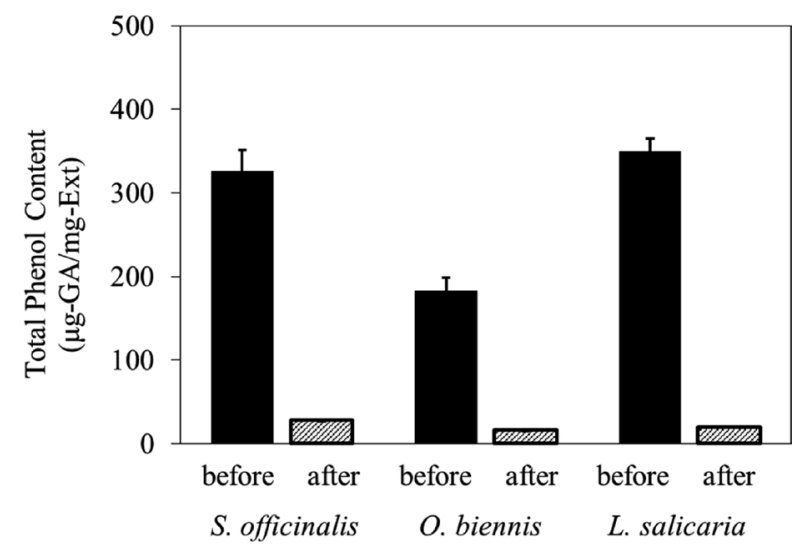

Fig. 4. Concentration of Total Phenolic Contents of Plant Extracts (Sanguisorba officinalis, Oenothera biennis, and Lythrum salicaria) before and after PVPP Treatment

ples did show high endotoxin activity, therefore, information regarding the endotoxin activity in PEL samples is meaningful.

The PEL samples for which the LAL test could not be performed normally, were derived from specific families such as Polygonaceae and Primulaceae (Table 3). These results suggested that common components in these plants can be involved in the reaction system. These plants are rich in polyphenol components, such as tannins. Polyphenol compounds are known to have several phenolic hydroxyl groups and inhibit the activity of various enzymes. ${ }^{30}$ ) Therefore, further experiments on the polyphenols in the plant extracts were conducted.

The interfering factors on the LAL test were divided into those that affect endotoxin and those that affect the LAL reaction system. The former includes surfactants, ${ }^{31)}$ metal ions, ${ }^{32)}$ and antibiotics, ${ }^{33)}$ and the latter includes proteases and their inhibitors and surfactants.

Similar reaction curves were obtained for all three plants before the addition of polymyxin B, which inactivate endotoxin by binding to the lipid A portion of endotoxin ${ }^{34,35)}$ (Fig. $3 \mathrm{~A} 2, \mathrm{~B} 2, \mathrm{C} 2$ ). If a plant extract affects endotoxin, the addition of polymyxin $\mathrm{B}$ would affect the reaction curve and recovery rate. However, such results were not observed in this study.

As endotoxin was measured using the colorimetric method in this study, the changes in absorbance at $405 \mathrm{~nm}$ can affect the measured values. Although most plant extract samples were brown to green, the samples diluted 100-fold with water for injection had no problem of coloring. The reaction between endotoxin and LAL reagent is a cascade reaction involving several enzymes ${ }^{3)}$; thus, there is a delay before the increase in absorbance. The extracts of S. officinalis, O. biennis, and L. salicaria showed changes in absorbance at $405 \mathrm{~nm}$ immediately after the start of the reaction (Figs. 3A1, B1, C1). Therefore, these initial changes in absorbance are not considered to be due to endotoxin.

Moreover, all reaction curves were sigmoid, and there were no initial changes in absorbance when the extracts were treated with PVPP, a resin that specifically adsorbs polyphenol [see Figs. 3A3, B3, C3. The recovery rates of these reactions were also within the allowable range (data not shown)]. These results suggested that the polyphenol components in the three plant extracts affected the LAL reaction system. Additionally, 
Table 4. Influence of Polyphenol Compounds and Concentrations on the Limulus Amoebocyte Lysate (LAL) Test

\begin{tabular}{|c|c|c|c|c|c|c|c|c|}
\hline \multirow{2}{*}{ No. } & \multirow{2}{*}{ Chemical name } & \multirow{2}{*}{ Compound group } & \multicolumn{3}{|c|}{ Recovery rate $(\%)^{a)}$} & \multicolumn{3}{|c|}{ Effect on reaction curves ${ }^{b)}$} \\
\hline & & & $1 \mu \mathrm{M}$ & $10 \mu \mathrm{M}$ & $100 \mu \mathrm{M}$ & $1 \mu \mathrm{M}$ & $10 \mu \mathrm{M}$ & $100 \mu \mathrm{M}$ \\
\hline 1 & Gallic acid & Benzoic acid derivative & 120 & 102 & 0 & - & $\mathrm{m}$ & $1, \mathrm{~m}$ \\
\hline 2 & Methyl gallate & & 133 & 150 & 209 & - & - & $1, \mathrm{~m}$ \\
\hline 3 & Vanillic acid & & 150 & 141 & 133 & - & - & - \\
\hline 4 & Ellagic acid & & 113 & 60 & 11 & - & $\mathrm{m}^{c)}$ & $\mathrm{m}, 1^{c)}$ \\
\hline 5 & trans-p-Coumaric acid & Phenylpropanoid & 117 & 129 & 139 & - & - & - \\
\hline 6 & trans-Caffeic acid & & 130 & 70 & 25 & - & - & - \\
\hline 7 & Ferulic acid & & 112 & 93 & 18 & - & - & - \\
\hline 8 & Chlorogenic acid & & 115 & 112 & 61 & - & $\mathrm{d}, 1$ & $\mathrm{~d}, 1$ \\
\hline 9 & Rosmarinic acid & & 130 & 100 & 59 & - & $\mathrm{d}, 1$ & $\mathrm{~d}, 1$ \\
\hline 10 & Hesperetin & Flavanone & 128 & 146 & 87 & - & - & - \\
\hline 11 & Naringenin & & 119 & 55 & 152 & - & $\complement^{c)}$ & - $^{c}$ \\
\hline 12 & Quercetin & Flavonol & 98 & -4662 & 0 & - & $\mathrm{d}^{c)}$ & $\mathrm{d}, \mathrm{l}^{c)}$ \\
\hline 13 & Rutin & & 152 & 134 & -127 & - & - & $\mathrm{d}, 1$ \\
\hline 14 & Genistein & Isoflavone & 112 & 112 & 67 & - & - & $\mathrm{m}^{c)}$ \\
\hline 15 & Puerarin & & 136 & 102 & 112 & - & - & - \\
\hline 16 & $(+)$-Catechin & Flavanol & 131 & 105 & 116 & - & - & - \\
\hline
\end{tabular}

a) Spike activity was $0.05 \mathrm{EU} / \mathrm{mL}$. b) Tested in the presence of $0.01 \%$ polymyxin B. Letters indicate: $\mathrm{m}$, meandering or deformation; d, decrease in absorbance at $405 \mathrm{~nm}$; 1 , disappearance of lag. c) Precipitation was observed.

as opposed to $S$. officinalis and L. salicaria, the $O$. biennis extract with the polyphenol removed showed a significant decrease in endotoxin activity. It is assumed that the polyphenol compounds contained in O. biennis had a LAL reactionpromoting action and thus resulted in higher-than-expected activity levels.

After revealing that polyphenol compounds affect the LAL test, we investigated the effects of single polyphenol compounds on the test. Compounds with caffeic acid derivative structures and pyrogallol structures were shown to affect the reaction of the LAL test (Table 4). Recovery rates outside of acceptable ranges and the deformation of the reaction curves were also observed for ellagic acid (4), quercetin (12), and genistein (14). However, these compounds have low water solubilities and, therefore, precipitation may affect the LAL reaction.

A very noteworthy result was the observation that caffeic acid derivatives had a prominent effect on the LAL test. Phenylpropanoids, such as caffeic acid, are important components of plants, e.g., in Compositae and Labiaceae. Caffeic acid derivatives are even the main polyphenol components of some plants. ${ }^{36)}$ For Aster leiophyllus Franch. var. leiophyllus (see Table 3, MPR-0400), the color of the test solution turned blue during measurement, thus indicating the involvement of compounds such as chlorogenic acid and rosmarinic acid. Previous reports have revealed that $S$. officinalis contains gallic acid, catechin, and ellagic acid derivatives ${ }^{37)}$; that $O$. biennis contains gallic acid ${ }^{38)}$; and that L. salicaria contains caffeic acid derivatives, gallic acid, and chlorogenic acid. ${ }^{39)}$

In this study, none of the compounds affected the LAL test at concentrations of $1 \mu \mathrm{M}$. Polyphenolic compounds have many analogs in plant extracts and are considered to be synergistic in the LAL test. In addition, having a large number of hydroxyl groups per molecule and a strong interaction with proteins, tannin has a higher potential of affecting LAL.
Further investigation is needed to investigate the effects of multiple polyphenolic compounds present at different concentrations, and to investigate the effects of polymers containing more phenolic hydroxyl groups.

\section{CONCLUSION}

In this study, we measured the endotoxin activity in PEL samples and determined its degree of contamination. Endotoxin was detected in 139 field-collected samples and 5 crude drug samples. Although the degree of contamination varied, it is suggested that the impacts of PEL samples on experiments with cells would be small. These insights on the activity of endotoxin greatly contribute to the improvement of the quality of our PEL.

More than 150 PEL samples were observed to have problems in their reaction courses or recovery rates in the LAL tests. The LAL tests with the three plant extracts (S. officinalis, O. biennis, and L. salicaria), indicated that the polyphenol compounds affected LAL test and that the effects differed depending on the plant species.

When 16 single polyphenol compounds were added to the LAL tests, the compounds with caffeoyl and pyrogallol moieties were found to affect the LAL reaction courses and recovery rates. In addition, none of the compounds had any effect at concentrations of $1 \mu \mathrm{M}$. Since there are various analogs of polyphenol compounds in plant extracts, it is assumed that they actually act synergistically. It is important to consider the recovery rates and reaction courses of LAL tests with samples containing polyphenol compounds.

Acknowledgments This research was supported by the Japan Agency for Medical Research and Development (Grant No. JP19ak0101046h0004). 
Conflict of Interest The authors declare no conflict of interest.

Supplementary Materials The online version of this article contains supplementary materials.

\section{REFERENCES}

1) Fuchino H, Kawakami H, Yoneyama $T$, Kawahara N. Recent research progress of research center for medical plant resources, National Institutes of Biomedical Innovation, health and nutrition (Part $3)$ - research project on medical plant resources for drug discovery-. PMDRS, 47, 787-791 (2016).

2) Tanamoto K. Endotoxin and the quality control of medicine. Bull. Natl. Inst. Health Sci., 126, 19-33 (2008).

3) Tsuchiya M. Endotoxin test. 2nd edition, Joho-Kiko, Tokyo (2015).

4) Grunfeld C, Zhao C, Fuller J, Pollack A, Moser A, Friedman J, Feingold KR. Endotoxin and cytokines induce expression of leptin, the ob gene product, in hamsters: a role for leptin in the anorexia of infection. J. Clin. Invest., 97, 2152-2157 (1996).

5) Khan MS, Coulibaly S, Abe M, Furukawa N, Kubo Y, Nakaoji Y, Kawase Y, Matsumoto T, Hasei T, Deguchi Y, Nagaoka H, Yamagishi N, Watanabe M, Honda N, Wakabayashi K, Watanabe T. Seasonal fluctuation of endotoxin and protein concentrations in outdoor air in Sasebo, Japan. Biol. Pharm. Bull., 41, 115-122 (2018).

6) Ohnishi T. Detection of endotoxin in Japanese mineral water for microbiological assessment of the water source and the factories. Jpn. J. Food Microbiol., 27, 141-145 (2010).

7) Brooks JP, Maxwell SL, Rensing C, Gerba CP, Pepper IL. Occurrence of antibiotic-resistant bacteria and endotoxin associated with the land application of biosolids. Can. J. Microbiol., 53, 616-622 (2007).

8) Levin J, Poore TE, Zauber NP, Oser RS. Detection of endotoxin in the blood of patients with sepsis due to Gram-negative bacteria. $N$. Engl. J. Med., 283, 1313-1316 (1970).

9) Morita $T$, Tanaka $\mathrm{S}$, Nakamura $\mathrm{T}$, Iwanaga $\mathrm{S}$. A new $(1 \rightarrow 3)-\beta$-Dglucan-mediated coagulation pathway found in Limulus amebocytes. FEBS Lett., 129, 318-321 (1981).

10) Iwanaga $S$, Miyata $T$, Tokunaga $F$, Muta $T$. Molecular mechanism of hemolymph clotting system in Limulus. Thromb. Res., 68, 1-32 (1992).

11) $\overline{\mathrm{He} Q}$, Lv Y, Yao K. Effects of tea polyphenols on the activities of $\alpha$-amylase, pepsin, trypsin and lipase. Food Chem., 101, 1178-1182 (2007).

12) Kandra L, Gyémánt G, Zajácz Á, Batta G. Inhibitory effects of tannin on human salivary $\alpha$-amylase. Biochem. Biophys. Res. Commun., 319, 1265-1271 (2004).

13) Park DH, Park SJ, Kim JM, Jung WY, Ryu JH. Subchronic administration of rosmarinic acid, a natural prolyl oligopeptidase inhibitor, enhances cognitive performances. Fitoterapia, 81, 644-648 (2010).

14) Niwa M, Milner KC, Ribi E, Rudbach JA. Alteration of physical, chemical, and biological properties of endotoxin by treatment with mild alkali. J. Bacteriol., 97, 1069-1077 (1969).

15) Fujita N, Saito Y, Nitto Y, Ito T, Mizuguchi H, Endo M, Ogata T. Folin-Chiocalteu colorimetric analysis using a scanner for rapid determination of total polyphenol content in many test samples. Stud. Sci. Technol, 1, 139-144 (2012).

16) Granica S, Piwowarski JP, Czerwińska ME, Kiss AK. Phytochemistry, pharmacology and traditional uses of different Epilobium species (Onagraceae): a review. J. Ethnopharmacol., 156, 316-346 (2014).

17) Granica S, Czerwińska ME, Piwowarski JP, Ziaja M, Kiss AK. Chemical composition, antioxidative and anti-inflammatory activity of extracts prepared from aerial parts of Oenothera biennis L. and Oenothera paradoxa Hudziok obtained after seeds cultivation. $J$.
Agric. Food Chem., 61, 801-810 (2013).

18) Srećković N, Stanković JSK, Matić S, Mihailović NR, Imbimbo P, Monti DM, Mihailović V. Lythrum salicaria L. (Lythraceae) as a promising source of phenolic compounds in the modulation of oxidative stress: comparison between aerial parts and root extracts. Ind. Crops Prod., 155, 112781 (2020).

19) Mohamed IH, Giorgio C, Bruni R, Flammini L, Barocelli E, Rossi D, Domenichini G, Poli F, Tognolini M. Polyphenol rich botanicals used as food supplements interfere with EphA2-ephrinA1 system. Pharmacol. Res., 64, 464-470 (2011).

20) World Health Organization. "WHO guidelines on good agricultural and collection practices (GACP) for medicinal plants.": 〈https:// apps.who.int/iris/bitstream/handle/10665/42783/9241546271.pdf, accessed 8 May, 2020.

21) Inagawa $H$, Nishizawa $T$, Tsukioka $D$, Suda $T$, Chiba Y. Okutomi T, Morikawa A, Soma G, Mizuno D. Homeostasis regulated by activated macrophage. II. LPS of plant origin other than wheat flour and their concomitant bacteria. Chem. Pharm. Bull., 40, 994-997 (1992).

22) $\mathrm{Hsu} \mathrm{Y} H, \mathrm{Fu}$ SL. Detection of endotoxin contamination in Chinese herbs by NF- $\kappa \mathrm{B}$ activity-based reporter assays. J. Food Drug Anal., 12, 34-39 (2004).

23) Guo C, Yuan L, Wang J, Wang F, Yang X, Zhang F, Song J, Ma X, Cheng Q, Song G. Lipopolysaccharide (LPS) induces the apoptosis and inhibits osteoblast differentiation through JNK pathway in MC3T3-E1 cells. Inflammation, 37, 621-631 (2014).

24) Zhang G, Han J, Welch EJ, Ye RD, Voyno-Yasenetskaya TA, Malik AB, Du X, Li Z. Lipopolysaccharide stimulates platelet secretion and potentiates platelet aggregation via TLR4/MyD88 and the cGMP-dependent protein kinase pathway. J. Immunol., 182, 79978004 (2009).

25) Ohkouchi Y, Ishikawa S, Takahashi K, Itoh S. Factors associated with endotoxin fluctuation in aquatic environment and characterization of endotoxin removal in water treatment process. Environ. Eng. Res., 44, 247-254 (2007).

26) Yang H, Kaneko M, He C, Hughes MA, Cherry GW. Effect of a lipopolysaccharide from E. coli on the proliferation of fibroblasts and keratinocytes in vitro. Phytother. Res., 16, 43-47 (2002).

27) Goodier MR, Londei M. Lipopolysaccharide stimulates the proliferation of human $\mathrm{CD}^{2} 6^{+} \mathrm{CD}^{-} \mathrm{NK}$ Cells: a regulatory role of monocytes and IL-10. J. Immunol., 165, 139-147 (2000).

28) Kirikae T, Tamura H, Hashizume M, Kirikae F, Uemura Y, Tanaka S, Yokochi T, Nakano M. Endotoxin contamination in fetal bovine serum and its influence on tumor necrosis factor production by macrophage-like cells J774.1 cultured in the presence of the serum. Int. J. Immunopharmacol., 19, 255-262 (1997).

29) Cho HH, Bae YC, Jung JS. Role of toll-like receptors on human adipose-derived stromal cells. Stem Cells, 24, 2744-2752 (2006).

30) Pohjala L, Tammela P. Aggregating behavior of phenolic compounds-A source of false bioassay results? Molecules, 17, 1077410790 (2012).

31) Ribi E, Anacker RL, Brown R, Haskins WT, Malmgren B, Milner KC, Rudbach JA. Reaction of endotoxin and surfactants. I. Physical and biological properties of endotoxin treated with sodium deoxycholate. J. Bacteriol., 92, 1493-1509 (1966).

32) Fujita Y, Nabetani T. Iron sulfate inhibits Limulus activity by induction of structural and qualitative changes in lipid A. J. Appl. Microbiol., 116, 89-99 (2014).

33) Hurley JC. Endotoxemia: methods of detection and clinical correlates. Clin. Microbiol. Rev., 8, 268-292 (1995).

34) Morrison DC, Jacobs DM. Binding of polymyxin B to the lipid A portion of bacterial lipopolysaccharides. Immunochemistry, 13, 813-818 (1976).

35) Tsuchiya M, Oishi H, Takaoka A, Fusamoto M, Matsuura S. Discrimination between endotoxin and $(1 \rightarrow 3)-\beta$-D-glucan using turbidimetric kinetic assay with Limulus amebocyte lysate. Chem. Pharm. 
Bull., 38, 2523-2526 (1990).

36) Yoshida T. Development of polyphenol-rich functional foods. (Yoshida T, Arii M eds.) CMC Publishing, Tokyo, pp. 3-11 (2007).

37) Su XD, Guo RH, Li HX, Ma JY, Kim YR, Kim YH, Yang SY. Anti-allergic inflammatory components from Sanguisorba officinalis L. Bioorg. Med. Chem. Lett., 28, 2210-2216 (2018).

38) Ahmad A, Ali M, Tandon S. New oenotheralanosterol A and B constituents from the Oenothera biennis roots. Chin. J. Chem., 28 2474-2478 (2010).

39) Rauha JP, Wolfender JL, Salminen JP, Pihlaja K, Hostettmann $\mathrm{K}$, Vuorela H. Characterization of the polyphenolic composition of Purple Loosestrife (Lythrum salicaria). Z. Naturforsch. C. J. Biosci., 56, 13-20 (2001). 